\title{
THE COMPLETE AMINO ACID SEQUENCE OF THE GLYCOPROTEIN, GLUCOAMYLASE G1, FROM ASPERGILLUS NIGER
}

\author{
by \\ BIRTE SVENSSON, KJELD LARSEN') \\ and \\ IB SVENDSEN
}

Carlsberg Laboratory, Department of Chemistry, Gamle Carlsberg Vej 10, DK-2500 Copenhagen Valby

and

\section{ESPER BOEL}

Laboratory of Genetics, NOVO Research Institute, Novo Allé, DK-2880 Bagsværd

1) Present address: Harvard Medical School, Center for Biochemical and Biophysical Sciences and Medicine, Seeley G. Mudd Bldg., 250 Longwood Ave., Boston, MA 02115

Keywords: Peptide sequencing, cyanogen bromide, hydroxylamine, oxidative halogenation, $\mathrm{S}$. aureus V8 protease, trypsin, endoproteinase Lys-C, deglycosylation, nucleotide sequencing

The primary structure of glucoamylase G1 (EC 3.2.1.3) from Aspergillus niger has been determined. Fragments of Gl were obtained by cleavage with either cyanogen bromide, hydroxylamine, or $\mathrm{S}$. aureus V8 protease. The resulting peptides were separated using ion exchange chromatography on DEAE-Sephacel, gel filtration, and affinity chromatography on Con A-Sepharose. Secondary fragments were generated by cleavage with either o-iodosobenzoic acid or BNPS-skatole as well as by digestion with S. aureus V8 protease, trypsin, and endoproteinase Lys-C. These peptides were purified by the procedures mentioned above and by reverse phase HPLC. The present fragments were amino acid sequenced and this permitted, in combination with the tryptic peptides (Carlsberg Res. Commun. 48, 517527 (1983)), identification of 574 of the 614 amino acid residues in G1. Sequencing of glucoamylase G1 cDNA, constructed from $A$. niger total mRNA, enabled deduction of the sequence of the remaining 40 amino acid residues localized to 6 short stretches. From the alignment of the fragments the complete primary structure of the enzyme was established. The amino acid sequence corresponds to a molecular weight of the polypeptide moiety of 65,424 . Including both hexosamine and neutral carbohydrate contents the molecular weight of the present sample of $\mathrm{Gl}$ was calculated to be about 82,000 .

The majority of the carbohydrate of $\mathrm{Gl}$ is found in a highly glycosylated region of 70 amino acid residues which comprises about $35 \mathrm{O}$-glycosyl serine and threonine residues. This region ends approximately 100 residues from the C-terminus of the enzyme. Two $\mathrm{N}$-glycosylated positions were found in the central part of the polypeptide chain. The molecule contains 9 half-cystine residues. No homology is apparent between the sequence of glycoamylase and various $\alpha$-amylases.

\footnotetext{
Abbreviations: BNPS-skatole = 2-(2-nitrophenylsulfenyl)-3-methyl-3'-bromoindolenine; $\mathrm{ca}=$ citraconyl; Con $\mathrm{A}=$ concanavalin A; DFP = diisopropylfluorophosphate; DPCC = diphenylcarbamyl chloride; EDTA = ethylenediaminetetraacetic acid, disodium salt; Hepes $=\mathrm{N}$-2-hydroxyethyl piperazine-N'-2-ethanesulfonic acid; Nemac = N-ethylmorpholine acetate; HPLC = high pressure liquid chromatography; PTH = phenylthiohydantoin; SDS-PAGE = polyacrylamide gel electrophoresis in the presence of sodium dodecyl sulfate; 2-pe = 2-pyridylethyl; Gl designates the larger and G2 the smaller of the forms of glucoamylase from A. niger (44).
} 


\section{INTRODUCTION}

Glucoamylases (1,4- $\alpha$-D-glucan glucohydrolase, EC 3.2.1.3) are industrially important enzymes, which catalyze the release of D-glucose from the non-reducing ends of starch and related oligo- and polysaccharides $(32,35)$. The glucoamylases are produced by a wide variety of microorganisms $(15,17,28,32,45,48)$. They frequently exist in multiple forms of which only the larger, referred to as $\mathrm{Gl}$, has the capacity to adsorb to and digest raw starch $(33,44,49)$. Partial amino acid sequence analysis of $\mathrm{Gl}$ and the smaller form $\mathrm{G} 2$ from $A$. niger suggested that the two forms have highly homologous structures, although $\mathrm{Gl}$ is extended with a C-terminal fragment that is lacking in G2 (44).

The glucoamylase from A. niger is an unusual glycoprotein. It is rich in mannose and carries a large number of short sugar units linked to serine and threonine $(33,34,44)$ which are mostly located in a highly glycosylated region comprising 70 amino acid residues (43). Evidence for a few additional attachment sites for carbohydrate outside this region has been obtained; among these are two $\mathrm{N}$-glycosylated asparagine residues.

In view of the wide commercial interest in glucoamylases and the future usefulness in studies of their structure-function relationships, we report the completion of the amino acid sequence of glucoamylase G1 from A. niger which has been achieved by a combination of results from peptide and cDNA sequencing.

\section{MATERIALS AND METHODS}

\subsection{Materials}

Homogeneous glucoamylase G1 from Aspergillus niger was prepared as described by Svensson et al. (44) from AMG 200L (Batch ASN 5192), a commercial preparation of the enzyme produced by Novo Industries, Bagsværd, Denmark.

Bio-Gels P-150, P-100, P-60, P-30, P-10, P-6, and P-2 were from Bio-Rad, Richmond, CA. DEAE-Sephacel and Con A-Sepharose were products of Pharmacia Fine Chemicals, Uppsala, Sweden. Dithiothreitol, DPCC-treated trypsin, DFP-treated carboxypeptidase B, cyanogen bromide, tryptamine hydrochloride, and nuclease S1 (EC 3.1.30.1; from Aspergillus oryzae) were from Sigma, St. Louis, MO. S. aureus V8 protease was from Miles, Stoke Poges, U.K.; endoproteinase Lys-C was from Boehringer, Mannheim, F.R.G.; 2-vinylpyridine was from Aldrich-Europe, Beerse, Belgium; o-iodosobenzoic acid and BNPS-skatole were from Pierce, Rockford, IL. Hydroxylamine hydrochloride, citraconic anhydride and tyramine hydrochloride were obtained from Merck, Darmstadt, F.R.G.. Trifluoroacetic acid was from Rathburn, Walkerburn, Scotland, as were reagents and solvents for the sequencer except ethylacetate which was from Merck. Carboxypeptidase $Y$ was prepared in this laboratory. Spectrapor dialysis tubings with cutoff at molecular weights of 3,500 and $6,000-8,000$ were from Spectrum medical Instruments, Los Angeles, CA. DNA polymerase I "Klenow fragment" (EC 2.7.7.7; from E. coli), and oligo(dT) $)_{12-18}$ were purchased from P-L Biochemicals, Milwaukee, WI. Reverse transcriptase (RNA-dependent DNA polymerase, EC 2.7.7.4; from avian myeloblastosis virus) was purchased from J.W. Beard, Life Sciences, St. Petersbourg, FL. Terminal deoxynucleotidyl transferase (EC 2.7.7.31) was from Bethesda Research Laboratories, Gaithersburg, MD. Restriction endonucleases were from New England BioLabs., Beverly, MA. RNasin (human placenta ribonuclease inhibitor) was from Biotec, Madison, WI. Oligo(dT)-cellulose was type T-2 from Collaborative Research, Waltham, MA. [ $\left.\alpha-{ }^{32} \mathrm{P}\right]-$ $\operatorname{dCTP}(3,200 \mathrm{Ci} / \mathrm{mmol})$ and $\left[\alpha^{-32} \mathrm{P}\right]-\mathrm{dATP}(3,200$ $\mathrm{Ci} / \mathrm{mmol}$ ) were obtained from New England Nuclear.

\subsection{Methods}

\subsubsection{Chemical modifications}

Glucoamylase $\mathrm{Gl}$ was dissolved $\left(60 \mathrm{mg} \cdot \mathrm{ml}^{-1}\right)$ in $7 \mathrm{M}$-guanidine hydrochloride, $0.2 \mathrm{M}$-Tris- $\mathrm{HCl}$ and 5 mu-EDTA pH 8.3 and treated with dithiothreitol followed by 2-vinylpyridine to yield 2-pyridylethylated G1, as earlier reported (12, 43). Citraconylation was performed a.m. DiXON and Perham and deglycosylation of peptides a.m. Mort and LAMPORT $(5,30,43)$.

\subsubsection{Procedures for cleavage of peptide bonds}

In order to ensure that the methionine residues were in the reduced state prior to cyanogen 
bromide cleavage, Gl was dissolved in the guanidine hydrochloride/Tris- $\mathrm{HCl}$ buffer (section 2.2.l) and treated with $5 \%$ ( $\mathrm{vol} / \mathrm{vol})$ 2-mercaptoethanol for 24 hours at room temperature (19). The solution was then dialyzed against $10 \%$ (vol $/ \mathrm{vol}$ ) ethanol, containing $0.1 \%$ 2-mercaptoethanol, and lyophilized. The reduced G1 was dissolved $\left(50 \mathrm{mg} \cdot \mathrm{ml}^{-1}\right)$ in $70 \%$ (vol/vol) trifluoroacetic acid containing $\mathrm{CNBr}$ (50 $\mathrm{mg} \cdot \mathrm{ml}^{-1}$ ) and tryptamine hydrochloride $\left(7.5 \mathrm{mg} \cdot \mathrm{ml}^{-1}\right)$. The reaction mixture was left for 20 hours, then 20 volumes of water was added and $\mathrm{CNBr}$ and solvent were removed by lyophilization. The cyanogen bromide fragments were reduced and alkylated (section 2.2.l) and subsequently separated by DEAE-Sephacel chromatography (section 2.2.3).

Cleavage with hydroxylamine was performed in principle as reported by BORNSTEIN and BALIAN (3). The freshly prepared reagent was $2 \mathrm{M}$-hydroxylamine in 6 M-guanidine hydrochloride, adjusted to $\mathrm{pH} 9.0$ with $4.5 \mathrm{M}$-lithium hydroxide and equilibrated for 5 minutes at $45^{\circ} \mathrm{C}$. 2-pe-G1 was dissolved $\left(2-5 \mathrm{mg} \cdot \mathrm{ml}^{-1}\right)$ immediately in the reagent and incubated for $2-4$ hours at $45^{\circ} \mathrm{C}$, during which period the $\mathrm{pH}$ was maintained at 9.0 by addition of lithium hydroxide. The reaction mixture was centrifuged, the supernatant obtained was passed through Bio-Gel P-2 in 0.05 M-ammonium bicarbonate to remove reagent and denaturant and the fragments were subsequently separated on Bio-Gel P-100.

Cleavage at the C-terminus of tryptophan residues was performed using either o-iodosobenzoic acid or BNPS-skatole according to procedures described by MAHONEY et al. (25) and FontANA et al. (10), respectively. All reactions were carried out in the dark at room temperature. o-Iodosobenzoic acid $\left(20 \mathrm{mg} \cdot \mathrm{ml}^{-1}\right)$ and tyramine hydrochloride $\left(4 \mathrm{mg} \cdot \mathrm{ml}^{-1}\right)$ in 4 M-guanidine hydrochloride and $80 \%$ in acetic acid were preincubated for 6 hours. The separated cyanogen bromide fragments were dissolved $\left(2-5 \mathrm{mg} \cdot \mathrm{ml}^{-1}\right)$ in the reagent and the solution was left for 22 hours. The reaction was then stopped by gel filtration on Bio-Gel P-6 in 30\% acetic acid. For each of the cyanogen bromide fragments the two pools of peptides obtained were lyophilized. The $\mathrm{C}$-terminal cyanogen bromide fragment $\left(2-8 \mathrm{mg} \cdot \mathrm{ml}^{-1}\right)$ was also cleaved by BNPS-skatole $\left(82 \mathrm{mg} \cdot \mathrm{ml}^{-1}\right)$ in $4 \mathrm{M}$-guanidine hydrochloride and $80 \%$ in acetic acid in the presence of tyrosine $\left(20 \mathrm{mg} \cdot \mathrm{ml}^{-1}\right)$. After 18 hours with stirring 20 volumes of water were added to the reaction mixture and BNPS-skatole was removed by extraction with diethylether. The aqueous phase was adjusted to $\mathrm{pH} 7.0$ with $\mathrm{NH}_{3}$, aq., and passed through Bio-Gel P-2 in $0.1 \mathrm{M}$-ammonium bicarbonate. The pool of peptides was lyophilized.

The N-terminal cyanogen bromide fragment (1 $\mathrm{mg} \cdot \mathrm{ml}^{-1}$ ) was digested with endoproteinase Lys-C $\left(1: 150, w t / w t ; 16\right.$ hours at $\left.37^{\circ} \mathrm{C}\right)$ in 0.06 M-ammonium bicarbonate $\mathrm{pH} 7.7$ (38). The C-terminal cyanogen bromide fragment (4 $\left.\mathrm{mg} \cdot \mathrm{ml}^{-1}\right)$ was digested with $\mathrm{S}$. aureus V8 protease $\left(1: 40\right.$, wt/wt; 3 hours at $\left.40^{\circ} \mathrm{C}\right)$ in $0.1 \mathrm{M}$-ammonium bicarbonate pH 7.8. Digestion of 2-peG1 $\left(1.2 \mathrm{mg} \cdot \mathrm{ml}^{-1}\right)$ with the same enzyme $(1: 40$, $\mathrm{wt} / \mathrm{wt}$; 12 hours at $40^{\circ} \mathrm{C}$ ) was carried out in 0.07 $\mathrm{M}$-sodium phosphate $\mathrm{pH} 7.6$ to achieve cleavage after both glutamic acid and aspartic acid residues (16). Peptide fragments $\left(2 \mathrm{mg} \cdot \mathrm{ml}^{-1}\right)$ were digested with trypsin (1:50, wt/wt; $2-4$ hours at $37^{\circ} \mathrm{C}$ ) in $0.1 \mathrm{M}$-ammonium bicarbonate $\mathrm{pH} 7.8$, $0.1 \mathrm{~mm}$-calcium chloride.

\subsubsection{Separation of peptides}

Cyanogen bromide fragments, some of their subfragments, and selected hydroxylamine fragments were purified on DEAE-Sephacel (1.6×60 $\mathrm{cm}$ ) which was equilibrated in 7 M-urea, 0.05 $\mathrm{M}$-Tris- $\mathrm{HCl} \mathrm{pH}$ 8.0. Elution was performed with this buffer $(200 \mathrm{ml})$ followed by a linear gradient from zero to $0.2 \mathrm{M}$-guanidine hydrochloride in the same buffer $(2 \times 600 \mathrm{ml})$. Pools of peptides were desalted by dialysis against $0.05 \mathrm{M}$-ammonium bicarbonate using Spectrapor dialysis tubing and lyophilized. Smaller peptides were desalted by gel filtration through Bio-Gel P-6 in either $0.05 \mathrm{M}$-ammonium bicarbonate or $30 \%$ acetic acid.

Separation of peptides (1-15 mg) by gel filtration was performed through either Bio-Gels P-150, P-100, P-60, P-30, P-10, or P-6 (1.5×90 $\mathrm{cm})$ in $0.2 \mathrm{M}$-ammonium bicarbonate $\mathrm{pH} 7.8$, unless otherwise specified.

Glycopeptides, generated by digestion with $\mathrm{S}$. aureus V8 protease or cleavage with BNPSskatole, were purified by affinity chromatogra- 
phy on Con A-Sepharose in principle as earlier described (43).

A Waters chromatograph was used for purification of peptides by reverse phase HPLC on a Wide Pore $\mathrm{C}_{18}$ column, i.d. $4.6 \mathrm{~mm}$ and length $25 \mathrm{~cm}$, from J.T. Baker Research Products (43). Elution was performed with linear gradients from $0.1 \%$ trifluoroacetic acid to $0.1 \%$ trifluoroacetic acid in 80\% 1- or 2-propanol (24).

\subsubsection{Amino acid sequence analysis}

Automated sequencing was performed with a Beckman Sequencer $890 \mathrm{C}$ and PTH-amino acids were identified as recently described $(8,18$, 20, 41, 43). PTH-2-pe-Cys was identified in the water phase. After oxidative halogenation PTHTyr coeluted with PTH-Val by HPLC. Digestion with carboxypeptidase B $(0.02 \mathrm{~mm})$ was performed at a molar ratio from 1:100 to 1:500 in $0.05 \mathrm{M}-\mathrm{Nemac} \mathrm{pH} 8.5$ at room temperature or in $0.05 \mathrm{M}$-Hepes $\mathrm{pH} 7.5$ at $40^{\circ} \mathrm{C}$. Carboxypeptidase $\mathrm{Y}(0.02 \mathrm{~mm})$ in $0.1 \mathrm{M}-\mathrm{Nemac} \mathrm{pH} 5.0$ at a molar ratio from 1:100 to 1:1000 was used either alone or after carboxypeptidase B. Aliquots were removed at appropriate time intervals and the amino acids released were determined.

\subsubsection{Preparation of $m R N A$}

Aspergillus niger cells growing at conditions optimized for glucoamylase production were pelleted at $10,000 \times \mathrm{g}$ and $4^{\circ} \mathrm{C}$ for 10 minutes. The pelleted cells were frozen in liquid nitrogen and stored at $\div 80^{\circ} \mathrm{C}$ until RNA extraction.

To extract the RNA, $5 \mathrm{~g}$ of frozen cells were pulverized under liquid nitrogen in a mortar. Quartz was added to disrupt the cell wall. The resulting powder was suspended in $60 \mathrm{ml}$ of a buffer containing $5 \mathrm{~m}$-guanidinium rhodanide, $50 \mathrm{~mm}$-Tris- $\mathrm{HCl}$ at $\mathrm{pH} 7.5,10 \mathrm{~mm}-\mathrm{EDTA}, 5 \%$ (vol/vol) 2-mercaptoethanol, 4\% (wt/vol) N-lauroylsarcosine, and $15 \%(\mathrm{wt} / \mathrm{vol}) \mathrm{CsCl}$. A few strokes with an Ultra Turrax homogenizer was used to decrease the viscosity of the suspension by shortening the length of chromosomal DNA from the cells. After pelleting insoluble material at $10,000 \times \mathrm{g}$ at $4^{\circ} \mathrm{C}$ for 15 minutes, total RNA was isolated from the supernatant as described (4) by pelleting through a $5.7 \mathrm{M}-\mathrm{CsCl} / 100 \mathrm{~mm}-\mathrm{EDTA}$ cushion in an SW41 Beckman rotor run at $37,000 \mathrm{rpm}$ for 18 hours at room temperature.
Poly(A)-containing RNA was obtained by two cycles of chromatography on oligo(dT)-cellulose (1).

\subsubsection{Construction and cloning of double- stranded glucoamylase G1 cDNA}

Double-stranded Aspergillus niger cDNA was synthesized and cloned on pBR327 in E. coli by procedures as described (2). Details of the cloning and the identification of glucoamylase Gl specific recombinants in the resulting cDNA library will be presented elsewhere.

\subsubsection{Analytical procedures}

The amino acid composition, contents of O-glycosylated serine and threonine residues, glucosamine, and neutral carbohydrate were determined as previously reported $(6,7,43)$. SDSPAGE was carried out for selected large fragments a.m. LAEMMLI (22) using 15\% acrylamide gels as earlier described (42). The DNA sequence of the inserts in glucoamylase G1 specific recombinants was determined by the chemical cleavage procedure (27).

\subsubsection{Peptide nomenclature}

Fragments obtained by cleavage of glucoamylase $\mathrm{Gl}$ with cyanogen bromide are named $\mathrm{CB}$ fragments and designated $\mathrm{CB} 1-\mathrm{CB} 3$, starting from the $\mathrm{N}$-terminus of the protein. The hydroxylamine fragments ( $\mathrm{Hy}$ ) and $\mathrm{S}$. aureus V8 protease fragments (E) from Gl are similarly numbered.

Secondary fragments purified after either cleavage at tryptophan residues (W), or digestions with trypsin (T), with trypsin after citraconylation ( $\mathrm{Tca}$ ), with endoproteinase Lys-C $(\mathrm{K})$, or with $\mathrm{S}$. aureus $\mathrm{V} 8$ protease $(\mathrm{E})$ are named according to their position in the primary fragment, viz. W2-CB1 is the second from the N-terminus of the isolated tryptophan peptides from CB1. The numbering of the tryptic fragments prepared from 2-pe-G1 and citraconylated 2-pe$\mathrm{Gl}$ is as published (43). Thus of the sequenced peptides found in pool 6 from the gel filtration through Bio-Gel P-100, T6-3 was the third to be released from the HPLC column (43). Localization of the fragments in the Gl sequence is often indicated by a parenthesis with the numbers of their $\mathrm{N}$ - and $\mathrm{C}$-terminal residues. 


\section{RESULTS}

\subsection{Cyanogen bromide fragments}

The glucoamylase G1 from A. niger contains two methionines. When the enzyme was cleaved with cyanogen bromide and the mixture of fragments was sequenced, the $\mathrm{N}$-termini of $\mathrm{CB1}$, $\mathrm{CB} 2$, and $\mathrm{CB} 3$ were found to be present in yields of $100 \%, 82 \%$, and $70 \%$, respectively. This improvement, compared with the previous results (44), is explained by the trifluoroacetic acid effecting better cleavage than the weaker formic acid of the Met-Ser bond (39). The 2-pyridylethylated $C B$ fragments were separated by ion exchange chromatography on DEAESephacel (Figure 1). Pool A contained CBI, while CB2 and CB3 were found in pools D and B, respectively. Pool $\mathrm{C}$ contained incompletely cleaved fragments. Materials from the different peaks within pool A (Figure 1) had essentially the same amino acid composition suggesting charge heterogeneity within $\mathrm{CB} 1$. Consistent with this, both aspartic acid and asparagine were found by the automated sequencing at positions 20 and 21 from the $\mathrm{N}$-terminus of CB1.

The amino acid composition, contents of O-glycosylated serine and threonine, glucosamine, and neutral carbohydrate were determined after rechromatography of the $\mathrm{CB}$ fragments (Table I) and agree with the results found for intact Gl. Deglycosylation of G1 by HF at $0{ }^{\circ} \mathrm{C}$ for 3 hours removed one glucosamine residue, suggested to be the residue found in CB3. From the absence of homoserine and homoserine lactone in CB3 and the identical N-terminal sequences of $C B 1$ and $G 1$ (44), the order of the fragments in the primary structure was established to be CB1(1-133)-CB2(134-396)-CB3(397614) (Figure 2). In Figure 2 (after page 542) are also aligned tryptic fragments (43) and the fragments discussed below, which enabled the reconstruction of the amino acid sequence of Gl.

\subsection{Hydroxylamine fragments}

The hydroxylamine fragments of G1 were separated by gel filtration on Bio-Gel P-100 (Figure 3). The subsequent steps of purification and the positions of the purified peptides in the sequence are listed in Table II. Hyl-Hy4 were generated by cleavage of Asn-Gly bonds, and Hy 5 by the exceptional cleavage of the Asn-Ser bond found

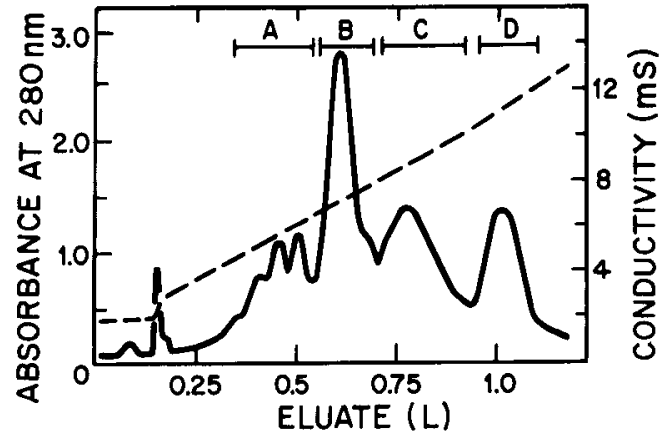

Figure 1. Separation of cyanogen bromide fragments (260 mg) on DEAE-Sephacel (see 2.2.3). Fractions of 11 $\mathrm{ml}$ were collected, pooled as indicated and subsequently rechromatographed in the same system. The CB fragments are described in Table I.

within Hy4. The apparent molecular weights of Hyl, Hy3, and $\mathrm{Hy} 4$ were estimated by SDSPAGE to be $11,000,16-19,000$, and 44,000 , respectively. The elution position of $\mathrm{Hy} 4$ from BioGel P-100 (Figure 3; Table II) suggested a folded conformation for this long fragment representing the C-terminal half of the polypeptide chain of G1.

\subsection{S. aureus $V 8$ protease fragments}

2-Pyridylethylated G1 was digested with S. aureus V8 protease in the presence of phosphate. The resulting glycopeptides were isolated by Con

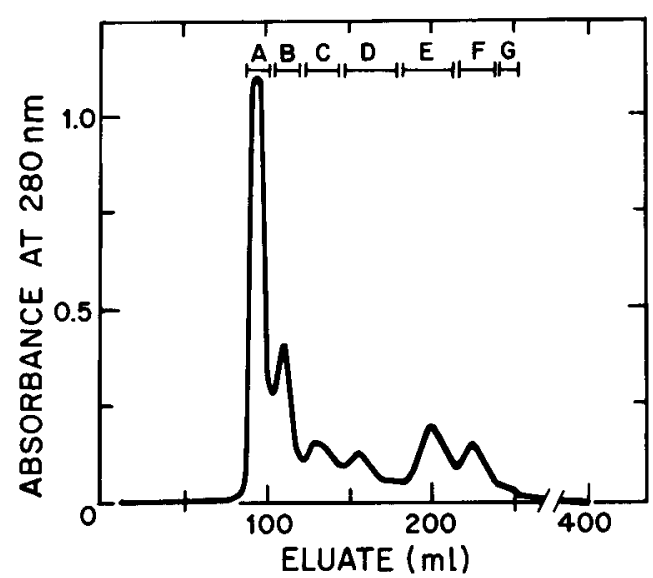

Figure 3. Separation of hydroxylamine fragments ( 21 $\mathrm{mg})$ on Bio-Gel P-100 $(2.5 \times 90 \mathrm{~cm})$. The indicated pools, $A, B, C, E$, and $F$ were further purified to give the fragments described in Table II. 
B. SvensSON et al.: Sequence of glucoamylase Gl

Table I.

Chemical characterization of cyanogen bromide fragments of glucoamylase G1 from Aspergillus niger.

\begin{tabular}{|c|c|c|c|c|c|c|c|c|}
\hline \multirow{3}{*}{$\begin{array}{l}\text { Amino acid } \\
\text { Aspartic acid }\end{array}$} & \multicolumn{5}{|c|}{ Residues/fragment } & \multicolumn{3}{|c|}{ Residues/protein } \\
\hline & \multicolumn{2}{|c|}{ CBI } & \multicolumn{2}{|c|}{$\mathrm{CB} 2$} & $\mathrm{CB} 3$ & \multirow{2}{*}{$\frac{\mathrm{CB}(1+2+3)}{68}$} & \multicolumn{2}{|c|}{ G1 } \\
\hline & 18.4 & (18) & 30.5 & (31) & $18.6 \quad(19)$ & & 67.3 & (67) \\
\hline Threonine $^{\text {a) }}$ & 11.6 & (12) & 19.6 & (20) & $40.6 \quad(41)$ & 73 & 72.5 & (73) \\
\hline Serine ${ }^{a l}$ & 15.1 & (15) & 33.8 & (34) & $33.9 \quad(34)$ & 83 & 83.6 & (84) \\
\hline Glutamic acid & 7.4 & ( 7$)$ & 21.1 & (21) & $15.0 \quad(15)$ & 43 & 43.2 & (43) \\
\hline Proline & 6.0 & (6) & 7.4 & ( 7$)$ & $8.9(9)$ & 22 & 22.9 & (23) \\
\hline Glycine & 13.4 & (13) & 17.4 & (17) & $15.2 \quad(15)$ & 45 & 45.3 & (45) \\
\hline Alanine & 14.0 & (14) & 26.7 & (27) & 21.0 & 62 & 62.0 & (62) \\
\hline Valine $^{\text {b) }}$ & 7.8 & ( 8$)$ & 16.8 & (17) & $14.6 \quad(15)$ & 40 & 40.3 & (40) \\
\hline Methionine & & & & & & & 2.2 & ( 2$)$ \\
\hline Isoleucine ${ }^{b)}$ & 6.7 & ( 7$)$ & 9.0 & (9) & $7.1 \quad(7)$ & 23 & 22.9 & (23) \\
\hline Leucine & 11.5 & (12) & 21.0 & (21) & 11.2 (11) & 44 & 45.1 & (45) \\
\hline Tyrosine & 4.3 & (4) & 14.3 & (14) & $9.0(9)$ & 27 & 27.0 & (27) \\
\hline Phenylalanine & 3.2 & (3) & 15.0 & (15) & $3.9(4)$ & 22 & 21.9 & (22) \\
\hline Histidine & 0.2 & $(0)$ & 3.8 & (4) & $0.3(0)$ & 4 & 4.2 & (4) \\
\hline 2-pe-Cysteinec) & 0.2 & $(0)$ & 4.6 & $(5)^{n}$ & $2.5(3)$ & 8 & 7.9 & ( 8 ) \\
\hline Lysine & 1.8 & ( 2$)$ & 4.6 & (5) & $4.5(5)$ & 12 & 11.5 & (12) \\
\hline Arginine & 5.7 & (6) & 6.3 & ( 6$)$ & $5.5(6)$ & 18 & 18.4 & (18) \\
\hline Homoserine ${ }^{d}$ & 0.7 & $(1)$ & 0.8 & ( 1$)$ & n.d. & 2 & & \\
\hline Tryptophane) & 3 & ( 3$)$ & 8 & ( 8$)$ & $7(7)$ & 18 & 18 & 18 \\
\hline Total number of residues & & 131 & & 262 & 221 & 614 & & 616 \\
\hline O-Glycosylated threonines) & 2.6 & (3) & 2.4 & ( 2) & $21.1 \quad(21)$ & & & \\
\hline O-Glucosylated serineg) & 0.7 & (1) & 4.2 & (4) & $16.0 \quad(16)$ & & & \\
\hline Neutral carbohydrate ${ }^{\text {hy }}$ & 5.3 & & 21 & & 73 & & & \\
\hline Glucosamine & trace & & 4.0 & & 1.0 & & & \\
\hline
\end{tabular}

a) Extrapolated to zero time of hydrolysis

b) Value after 72 hours of hydrolysis

c) 2-Pyridylethyl-cysteine (12)

d) Sum of homoserine and homoserine lactone; n.d. means not detecled

e) From the sequence determination

f) By sequencing, six 2-pe-Cys were found in CB2

g) Determined by reductive $\beta$-elimination followed by amino acid analysis (6)

h) Determined by the phenol-sulfuric acid procedure (7) using mannose as standard

i) Determined on the amino acid analyzer after acid hydrolysis (43)

The sizes of the $\mathrm{CB}$ fragments were based on: $\mathrm{CB1}, 6$ Pro and $14 \mathrm{Ala} ; \mathrm{CB} 2,21$ Leu and 15 Phe; $\mathrm{CB} 3,15$ Glu and 21 Ala. The apparent molecular weights were found by SDS-PAGE to be $40,000,35,000$, and 12,000 for CB2, CB3, and CBI, respectively.

A-Sepharose chromatography and subsequently separated by gel filtration through Bio-Gel P-60 which led to isolation of a large, glycosylated fragment, E1(438-518), with C-terminal aspartic acid. Digestion of El with carboxypeptidase $Y$ was performed after deglycosylation. A dominating front peak containing E1-CB2(298-387, and in part 298-340) was obtained by separation of $\mathrm{S}$. aureus V8 protease digests of $\mathrm{CB} 2$ on BioGel P-100. The fragments obtained from CB3 by digestion with the $S$. aureus V8 protease were separated on DEAE-Sephacel (Figure 4). Two peptides were purified by gel filtration of pool $A$ on Bio-Gel P-6. One was similar to El and the 
Table II.

Purification of hydroxylamine fragments after separation on Bio-Gel P-100.

\begin{tabular}{clc}
\hline $\begin{array}{c}\text { Pool } \\
\text { (Figure 3) }\end{array}$ & Purification procedure & Fragment \\
\hline A & Bio-Gel P-150 & Hy3 (181-311) \\
B & DEAE-Sephacel, eluted at 0.07 M-GuHC & Hy4 (312-614) \\
C & Bio-Gel P-60 & Hy5 (429-614) \\
E & DEAE-Sephacel, eluted at 0.03 M-GuHCl followed by Bio-Gel P-60 in 0.02 & \\
& M-GuHCl, 0.05 M-Tris-HCl, pH 7.6 & Hy1 ( 68-143) \\
F & Bio-Gel P-100 followed by Bio-Gel P-60 & Hy2 (144-180) \\
\hline
\end{tabular}

Chromatography on DEAE-Sephacel was followed by rechromatography in the same system. Gel filtration was performed as described in section 2.2.3 except in the case of Hyl. Hy5 is not included in Figure 2.

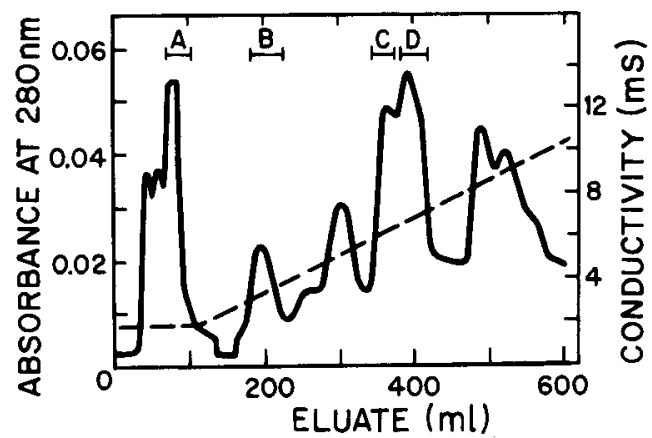

Figure 4. Separation of S. aureus V8 protease fragments from CB3 on DEAE-Sephacel $(1.6 \times 35 \mathrm{~cm})$. Fractions of $5.5 \mathrm{ml}$ were collected, pooled (indicated by bars) and further purified as described in 3.3 .

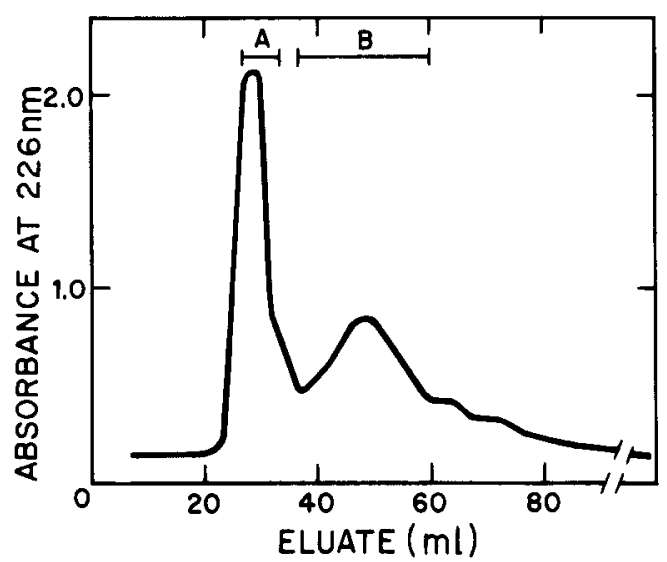

Figure 5. Separation on Bio-Gel P-60 of the larger fragments $(4 \mathrm{mg})$ obtained by cleavage of $\mathrm{CB} 2$ with o-iodosobenzoic acid. The pools $A$ and $B$ were subjected to automated sequencing. other was E3-CB3(596-614), the C-terminal fragment of the protein (Figure 2). Pool B contained the N-terminal fragment of CB3, Ser(397)Glu(437). Pools C and D were further purified by gel filtration on Bio-Gel P-6 and P-10, respectively, to yield E1-CB3(528-542) and E2CB3(543-574).

\subsection{Tryptophan fragments}

Fragments of $\mathrm{CB} 1$ obtained by treatment with o-iodosobenzoic acid were separated when the reagents were removed by gel filtration through Bio-Gel P-6 (see 2.2.2). Automated sequencing of the front pool showed W1-CB1, starting at $\operatorname{Thr}(51)$, to be a major component. Thus cleavage had occurred after $\operatorname{Tyr}(50)$ (Figure 2) even in the presence of tyramine hydrochloride. The smaller peptides in the second pool were separated by HPLC; W2-CB1(119-133) eluted at 18\% 1-propanol.

The larger peptides generated by cleavage of CB2 with o-iodosobenzoic acid were fractionated on Bio-Gel P-100 (Figure 5). Pool A contained W1-CB2, which could only be sequenced for a few cycles because of a sudden drop in repetitive yield at Asn(180), probably due to reactions with the peptide bond to the adjacent Gly(181) (Figure 2). Pool B contained W2CB2(227-315).

The fragments obtained by o-iodosobenzoic acid cleavage of CB3 were separated by DEAESephacel chromatography (Figure 6). Pools A, B, and $C$ were passed through Bio-Gel P-30 to give 
W2-CB3(465-541, with a significant content of 465-530), W1-CB3(435-464) (not shown in Figure 2), and W4-CB3(562-588), respectively. Both W1-CB3 and W2-CB3 were sequenced before and after deglycosylation. Fragments of CB3 were also prepared by cleavage with BNPSskatole and separated on Bio-Gel P-30 (Figure 7). The pool A was passed through Con A-Sepharose. The non-adsorbed and the adsorbed fractions were subsequently fractionated on Bio-Gel P-30 to yield W3-CB3(542-561) and W5-CB3(589-613), which coeluted with equimolar amounts of W1-CB3(435-464). The type of bond between the two latter peptides was not identified, but a disulfide might have formed from Cys(447) and Cys(602) as a result of incomplete reduction and alkylation. When sequencing W5-CB3, no vacant positions were observed and this would indicate the absence of carbohydrate side chains. However, it cannot be excluded that the fragment was retained on Con A-Sepharose because some of the serine and threonine residues were partially glycosylated.

\subsection{Digestions with endoproteinase Lys-C and trypsin}

The digest of CB1 with endoproteinase Lys-C was fractionated on Bio-Gel P-60 (Figure 8). Pool A contained K1-CB1(60-106) and pool B K2-CB1 (107-133, and significant amounts of 108-133). A chymotrypsin-like specificity of an endoproteinase Lys-C preparation was previously observed (38). The same bond, Phe(107)Asn(108), was also susceptible to trypsin. The only other example in G1 of trypsin catalyzing the hydrolysis at an atypical residue seemed to be in the case of fragment Tca2-1, terminated by Phe(517) (43).

In addition to the tryptic fragments from 2-peG1 and citraconylated 2-pe-Gl earlier described (43) and shown in Figure 2, a few tryptic subfragments, which have been useful for the reconstruction of the amino acid sequence, were prepared. Thus Hy3(181-311) was citraconylated and digested with trypsin. Fractionation by HPLC resulted in Tcal-Hy3(272-284) eluting at 16\% 2-propanol. Digestion of CB2 with trypsin and isolation of the smaller peptides by HPLC resulted in T1-CB2(336-350), which eluted at $26 \%$ 1-propanol and had not been isolated from

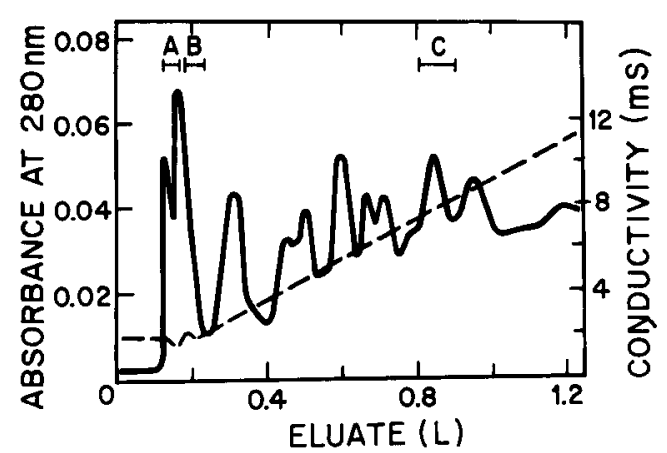

Figure 6. Separation on DEAE-Sephacel of fragments from CB3 obtained by cleavage with o-iodosobenzoic acid. Pools A, B, and C, were separately further purified on Bio-Gel P-30.

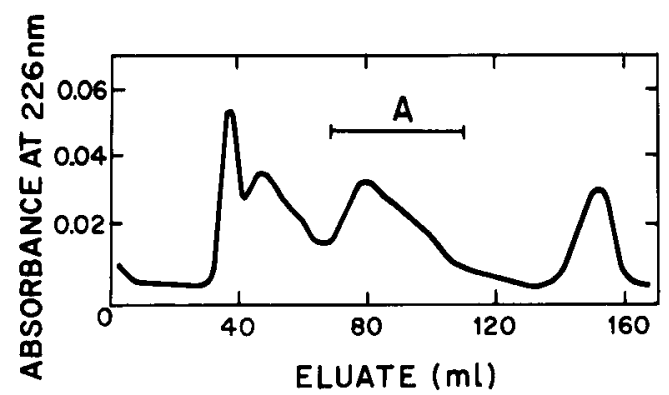

Figure 7. Separation on Bio-Gel P-30 of fragments from CB3 $(2 \mathrm{mg}$ ) obtained by cleavage with BNPS-skatole. Pool A was further fractionated by affinity chromatography on Con A-Sepharose, described in 3.4.

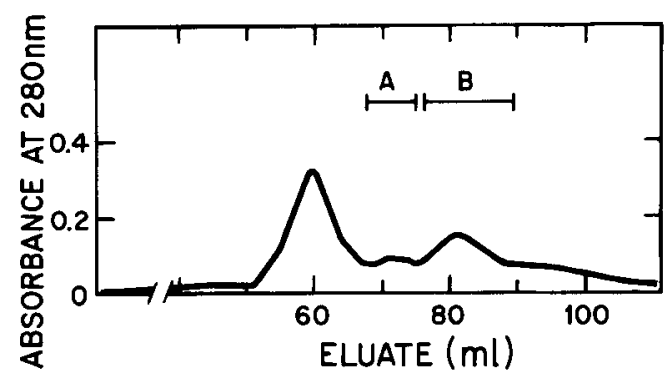

Figure 8. Separation on Bio-Gel P-60 of fragments (1.5 $\mathrm{mg}$ ) from CB1 obtained by digestion with endoproteinase Lys-C. Pools A and B were subjected to automated sequencing.

tryptic digests of 2-pe-G1. Other isolated peptides were T6-2, T6-3 (243-271, not shown in Figure 2), T7-3, T8-3 described in an earlier publication (43), and T8-3+T7-3(272-284) which eluted 
Table III.

Nucleotide sequences enabling the determination of the complete amino acid sequence of glucoamylase G1 from A. niger.

\begin{tabular}{llllll}
\hline A. Amino acid residues identified only from the cDNA sequence data \\
\hline UCU & CCG GCU CUG & AAC & CAC & GCA UGC GAC GAC UCC ACC UUC CAG CCC \\
Ser & Pro - Ala - Leu & Asn & His & Ala - Cys - Asp - Asp - Ser - Thr - Phe - Gln - Pro \\
93 & 126 & 169 & 191 & 259
\end{tabular}

$\begin{array}{ll}\text { AGU GAC AGC } & \text { ACU UAU AGU AGC AUU GUA GAU GCC GUG } \\ \text { Ser - Asp - Ser } & \text { Thr - Tyr - Ser - Ser - Ile - Val - Asp - Ala - Val } \\ 294 & 367 \\ & \\ \text { CCC ACC GCC } & \text { CUG ACA GCU ACC ACC ACC UAC GGC GAG } \\ \text { Pro - Thr - Ala } & \begin{array}{l}\text { Leu - Thr - Ala - Thr - Thr - Thr - Tyr - Gly - Glu } \\ 510\end{array} \\ 519\end{array}$

\begin{tabular}{llll}
\hline B. Confirmation of non-overlapping peptide sequences & \\
\hline CCG CGC GCG CUC & UUC CGC UCA AUC & GUG AAG ACU UUC & AGC AAG ACC AGC \\
Pro - Arg - Ala - Leu & Phe - Arg - Ser - Ile & Val - Lys - Thr - Phe & Ser - Lys - Thr - Ser \\
270 & 283 & 375 & 496 \\
& & & \\
UUC GAU CUG ACA & UAC GGC GAG AAC & \\
Phe - Asp - Leu - Thr & Tyr - Gly - Glu - Asn & & \\
517 & 525 & &
\end{tabular}

at 14\% 1-propanol. Digestion of T7-3(278-284) by carboxypeptidases $\mathrm{B}$ and $\mathrm{Y}$ in combination released stoichiometric amounts of Arg, Phe and Asp. However, a component eluting between $\mathrm{Thr}$ and Asp in the chromatogram of amino acids, suggested the serine residue which was identified by amino acid analysis after acid hydrolysis of T7-3, to be modified. A tryptic subfragment of Hy2, Asn(159)-Asn(180), was eluted at 33\% 1-propanol. It contained 1.6 residues of glucosamine, probably bound to the Asn(169) which has been identified by nucleotide sequencing (Table III). The highly glycosylated fragment, Tca2-1 (43) was digested with carboxypeptidase $Y$ after deglycosylation resulting in identification of the five $\mathrm{C}$-terminal residues.

\subsection{Molecular cloning of glucoamylase specific cDNA}

An oligo(dT) primed cDNA library synthesized from A. niger poly(A)-containing RNA was constructed and screened for glucoamylase specific recombinants. DNA restriction fragments were generated from clones with a cDNA
AGC

Ser

489

complementary to glucoamylase mRNA, and labeled with radioactive deoxynucleoside triphosphates by DNA polymerase for DNA sequencing. By this approach sequence information corresponding to the glucoamylase mRNA was obtained and used to determine regions of the primary structure of $\mathrm{A}$. niger glucoamylase (Table III).

\section{DISCUSSION}

The complete amino acid sequence of glucoamylase G1 from Aspergillus niger was reconstructed from cyanogen bromide, tryptic (43), and hydroxylamine fragments in combination with cDNA sequencing data. The tryptic fragments T7-8 and T5-1 (Tca3-1) contained overlapping sequences for the cyanogen bromide fragments (43). Fourty out of the 614 amino acid residues have been deduced from the nucleotide sequence of cloned glucoamylase G1 cDNA.

Chemical analysis of $\mathrm{CB1}$, the N-terminal cyanogen bromide fragment, indicated a low content of carbohydrate and O-glycosylated amino acid residues. Two positions likely to be 
glycosylated are $\operatorname{Thr}(47)$ and $\operatorname{Ser}(93)$. Both were vacant in automated sequencing, but they have tentatively been identified from the amino acid composition of the highly purified and otherwise fully sequenced tryptic fragments T6-4 and T5-2, respectively (43). $\operatorname{Ser}(93)$ has been confirmed by the cDNA sequence (Table III). Since no other vacant positions were observed during automated sequencing of either $\mathrm{CB} 1$ or fragments from this region of $\mathrm{Gl}$, other positions can only be partially glycosylated. A short tryptic fragment, T8-1, was isolated after tryptic digestion of 2-pyridylethylated G1, CB1, or K2-CB1. Surprisingly T8-1 seemed unsusceptible to carboxypeptidases $B$ and $Y$ and the sequence Pro(126)-Leu(128) was established from the nucleotide sequence (Table III).

The central cyanogen bromide fragment, $\mathrm{CB} 2$, contained 4 glucosamine residues, suggesting the presence of two $\mathrm{N}$-glycosylated units with the common pentasaccharide core (29). One site has been identified by dansyl Edman- degradation of Tca3-1 (43) to be Asn(393). Accordingly, two glucosamine residues were found in each of T5-1, Tca3-1, and a short peptide, $\operatorname{Thr}(388)-$ Hse(396) which was obtained by digestion of CB2 with S. aureus V8 protease. Previous experiments had indicated the content of neutral carbohydrate associated with $\operatorname{Asn}(393)$ to be equivalent to 8 mannosyl residues (43). The second glycosylated position in CB2 is suggested to be Asn(169). A tryptic fragment from $\mathrm{Hy2}$, Asn(159)-Asn(180), contained 1.6 glucosamine residues and furthermore the requirement of an Asn-X-Ser/Thr sequence for glycosylation (26) would be fulfilled for Asn(169). The cDNA-sequence confirmed Asn at position (169) (Table III). No other vacant positions were found by automated amino acid sequencing of the region covered by $\mathrm{CB} 2$ and asparagine residues were not represented in the short stretches obtained by the cDNA-sequence. Thus Asn(169) and Asn(393) are suggested to be the only two fully glycosylated asparagine residues of Gl. The only other potential site of $\mathrm{N}$-glycosylation, Asn(180), appeared not to carry carbohydrate, since it was identified in automated peptide sequencing and the Asn(180)-Gly(181) bond was susceptible to cleavage with hydroxylamine. No residues in $\mathrm{CB} 2$ have been assigned as O-glycosylated. Per- haps $\operatorname{Ser}(282)$, which appears to be modified, carries carbohydrate (see 3.5). Indeed chemical analysis indicated the presence of O-glycosylated residues in CB2 (Table I). It is, however, assumed that they exist only as partially glycosylated positions, which would enable the determination of the amino acid sequence on the fraction of unglycosylated residues. Furthermore, it cannot be excluded that the hydroxyamino acid residues identified only by nucleotide sequencing carry carbohydrate.

The sequenced parts of Tcal-1(193-239) and W2-CB2(227-315) are overlapped by $\operatorname{Thr}(227)$ only. However, amino acid compositions of both fragments and the part of W2-CB2 overlapping with Tca3-2(240-271) justified the alignment. Tca3-2 and T6-3(243-271) (see reference 43) have only been sequenced to $\mathrm{Ala}(258)$ by peptide sequencing, while Ala(259)-Pro(267) was deduced from the nucleotide sequence (Table III). Tcal-Hy3(272-284) could only fit in $\mathrm{Hy} 3$ between Tca3-2 and T6-2 and the overlapping sequences were confirmed by cDNA-sequencing (Table III). Interestingly carboxypeptidase $Y$ was observed to possess the capacity to release C-terminal 2-pyridylethyl-cysteine, from Tca3-2. T8$3(272-277)$ and T7-3(278-284) were found in tryptic digests of both 2-pyridylethylated Gl and CB2. The Lys(277)-Glu(278) bond seemed to be slowly hydrolyzed by trypsin, since T8-3 and T8$3+\mathrm{T} 7-3(272-284)$ were isolated in equimolar amounts by HPLC of tryptic digests of CB2. Presumably the adjacent $G l u(278)$ impeded the action of trypsin at Lys(277). In T6-2, the sequence Ser(294)-Ser(296) was deduced from the cDNA (Table III). The alignment of T7-4 and T5-1 was also confirmed by nucleotide sequencing. In T7-4 the segment represented by $\operatorname{Thr}(367)$ $\mathrm{Val}(375)$ was deduced from the cDNA sequence (Table III).

The C-terminal cyanogen bromide fragment, $\mathrm{CB} 3$, comprises the region characterized by a high frequency of glycosylated residues, which has recently been described in detail (43). Nucleotide sequencing confirmed that T2-dTca2-1 (498-517) follows Lys(497) as previously concluded (43); the sequence Pro(510)-Ala(512) was determined from the cDNA (Table III). The exact glycosylation pattern in the C-terminal part of the glycosylated region, $\operatorname{Thr}(498)-\operatorname{Thr}(511)$, is 
Table IV.

Amino acid composition of G1 and CB fragments from the amino acid sequence and from amino acid analysis.

\begin{tabular}{|c|c|c|c|c|c|c|c|c|}
\hline \multirow[t]{2}{*}{ Amino acid } & \multicolumn{6}{|c|}{ Residues/fragment } & \multicolumn{2}{|c|}{ Residues/G1 } \\
\hline & CBI & & $\mathrm{CB} 2$ & & CB3 & & & \\
\hline $\begin{array}{l}\text { Aspartic acid } \\
\text { Asparagine }\end{array}$ & $\left.\begin{array}{r}10 \\
8\end{array}\right\}$ & (18) & $\left.\begin{array}{l}21 \\
11\end{array}\right\}$ & $(31)$ & $\left.\begin{array}{r}12 \\
5\end{array}\right\}$ & $(19)$ & $\left.\begin{array}{l}43 \\
24\end{array}\right\}$ & $(67)$ \\
\hline Threonine & 12 & $(12)$ & 19 & $(20)$ & 42 & $(41)$ & 73 & (73) \\
\hline Serine & 15 & $(15)$ & 34 & (34) & 35 & $(34)$ & 84 & (84) \\
\hline $\begin{array}{l}\text { Glutamic acid } \\
\text { Glutamine }\end{array}$ & $\left.\begin{array}{l}4 \\
3\end{array}\right\}$ & $(7)$ & $\left.\begin{array}{l}11 \\
10\end{array}\right\}$ & $(21)$ & $\left.\begin{array}{r}11 \\
4\end{array}\right\}$ & $(15)$ & $\left.\begin{array}{l}26 \\
17\end{array}\right\}$ & $(43)$ \\
\hline Proline & 6 & $(6)$ & 7 & $(7)$ & 9 & ( 9) & 22 & (23) \\
\hline Glycine & 14 & (13) & 17 & $(17)$ & 14 & $(15)$ & 45 & (45) \\
\hline Alanine & 15 & (14) & 27 & $(27)$ & 21 & $(2 \mathrm{I})$ & 63 & $(62)$ \\
\hline Valine & 8 & $(8)$ & 17 & $(17)$ & 15 & $(15)$ & 40 & $(40)$ \\
\hline Methionine & 0 & $(0)$ & 0 & $(0)$ & 0 & $(0)$ & 2 & ( 2) \\
\hline Isoleucine & 7 & $(7)$ & 9 & (9) & 7 & (7) & 23 & (23) \\
\hline Leucine & 12 & $(12)$ & 21 & $(21)$ & 10 & (11) & 43 & $(45)$ \\
\hline Tyrosine & 4 & $(4)$ & 14 & $(14)$ & 9 & $(9)$ & 27 & $(27)$ \\
\hline Phenylalanine & 3 & ( 3$)$ & 15 & $(15)$ & 3 & (4) & 21 & (22) \\
\hline Histidine & 0 & $(0)$ & 4 & (4) & 0 & $(0)$ & 4 & (4) \\
\hline Lysine & 2 & $(2)$ & 5 & $(5)$ & 5 & $(5)$ & 12 & $(12)$ \\
\hline Arginine & 6 & $(6)$ & 6 & $(6)$ & 6 & $(6)$ & 18 & (18) \\
\hline Homoserine & 1 & $(1)$ & 1 & $(1)$ & 0 & $(0)$ & & \\
\hline 2-pe-Cysteine & 0 & $(0)$ & 6 & $(5)$ & 3 & ( 3) & 9 & ( 8$)$ \\
\hline Tryptophan & 3 & & 8 & & 7 & & 18 & \\
\hline
\end{tabular}

The values in parenthesis were determined by amino acid analysis.

still unknown, because the protein sequencing was performed only on the deglycosylated peptide (43). However, from both the number of identified and the total number of O-glycosylated positions in Tca2-1, the majority of the residues in T2-dTca2-1 are suggested to be glycosylated (43). In addition CB3 was found to contain one residue of glucosamine, which has not been located in the primary structure. The absence of Asn-X-Ser/Thr sequences in CB3 excludes the possibility of a partially $\mathrm{N}$-glycosylated residue. In agreement with the suggested localisation in an O-glycosidically linked oligosaccharide unit, one residue of glucosamine was lost upon HFdeglycosylation of G1. The residues in the segment Leu(519)-Gly(526) were only determined from the cDNA (Table III). The different C-terminal sequence reported earlier for G1 (44) probably reflects the difficulties encountered in interpretation of results from carboxypeptidase digestion of the long polypeptide chain.
The amino acid composition of the three $C B$ fragments and of $\mathrm{Gl}$ obtained by amino acid analysis, were compared with the composition calculated from the amino acid sequence (Table IV). Only minor differences were observed. Generally the contents of 2-pe-cysteine were lower than the number of half-cystines (Tables I and IV). In the CB3 fragment the phenylalanine content was approximately $25 \%$ too high, perhaps due to the presence of a hydrolysis resistant compound coeluting with phenylalanine in the chromatogram of amino acids. The $\mathrm{N}$-terminal $\mathrm{CB}$ fragment was low in alanine, threonine, and leucine (Table I). This probably reflects that a fraction of the G1 molecules exist in a form which lacks the three N-terminal residues (44). As can be seen from Table IV the content of asparagine in $\mathrm{Gl}$ was $56 \%$ of that of aspartic acid residues and the content of glutamine was $65 \%$ of the glutamic acid content. Along the polypeptide chain the frequency of the amides was rather constant 
in $\mathrm{CB} 1$ and $\mathrm{CB} 2$, whereas the acids dominated in CB3. This is in agreement with $\mathrm{G} 2$ having a higher isoelectric point than Gl (44).

Earlier attempts to determine the molecular weight of glucoamylase $\mathrm{G} 1$ gave values varying from 52,000 to $110,000(11,23,33,35,44)$. From the complete amino acid sequence the molecular weight of the polypeptide chain was calculated to be 65,424 . The carbohydrate contents of the present preparation of $\mathrm{G} 1$, determined from the separated CB fragments, were 99 residues of neutral carbohydrate (mannose equivalents) plus five residues of glucosamine assumed to be $\mathrm{N}$-acetylated. This corresponds to a molecular weight of the carbohydrate moiety of 17,053 . Thus the molecular weight of the present preparation of glucoamylase G1 from Aspergillus niger was calculated to be $82,477^{x}$ ). In the literature, varying contents of neutral carbohydrate from $8-20 \%$ (wt/wt) and no content of hexosamine have been reported for Gl from A. niger (35). However, a few other fungal glucoamylases contain hexosamine $(17,35,45)$.

No homology was apparent between the primary structures of $\mathrm{Gl}$ and $\alpha$-amylases described in the literature $(14,21,31,37,46,47)$. Three fungal carbohydrases, a mycodextranase (36), a cellobiohydrolase $(9,13)$, and the glucoamylase Gl $(34,44)$, which all attack insoluble substrates, i.e. fungal cell wall polysaccharides, cellulose, and raw starch, respectively, are all glycoproteins carrying an unusually large number of short O-glycosidically linked oligosaccharide units. Recently the determination of the amino acid sequence of the cellobiohydrolase (9) was completed by aid of molecular cloning (40), but no sequence homology was found between this enzyme, which possesses a glycosylated region of about 15 amino acid residues, and glucoamylase Gl. It is still not known, whether the glycosylated region is required for the formation of the insolu-

$x)$ Recent experiments in this laboratory have reinvestigated the sedimentation equilibrium behaviour of G1. The molecular weight was now in better agreement with the calculated value. The reason for the much lower published value of $52,000(44)$ is in part, that a very long period of time was needed to reach equilibrium (Ms. Hanne Møller and Dr. Torben Graves Pedersen, unpublished observations). ble enzyme substrate complexes. However, G2 does not digest raw starch, but is glycosylated to the same extent as Gl (44). Moreover it has a $\mathrm{C}$-terminus corresponding to a position near the C-terminal end of the glycosylated region in G1. This suggests that other structural features are required to achieve digestion of the insoluble polysaccharides.

The glucoamylase Gl sequence presented has very recently been confirmed from residue 55 to 614 by the sequence of cDNA clones constructed from the G1 mRNA (to be published elsewhere).

Note added in proof: Recently, sequencing of cDNA synthesized complementary to the 5' end of the Gl mRNA suggests Asp in position (47) and the sequence Thr-Trp to be inserted between $\operatorname{Tyr}(50)$ and $\mathrm{Thr}(51)$ in Figure 2.

\section{ACKNOWLEDGEMENTS}

We are grateful to Professor MARTin OTtESEN and Dr. NifLS P. Fill for helpful discussions and encouragement during all stages of this work. Mss. Edith Fløistrup and IbEN Huort are thanked for outstanding technical assistance with preparation and characterization of peptide fragments and nucleotide sequencing, respectively. Mss. Lone Sørensen, Bodil CorNeliussen, Sidsel Ehlers and Pia Breddam are acknowledged for technical assistance with amino acid analysis and sequencing. Dr. ANTHONY ClARKE is thanked for linguistic correction of the manuscript.

\section{REFERENCES}

1. Aviv, H. \& P. Leder: Purification of biologically active globin messenger RNA by chromatography on oligothymidylic acid-cellulose. Proc. Natl. Acad. Sci. USA 69, 1408-1412 (1972)

2. Boel, E., J. Vuust, F. Norris, K. Norris, A. WIND, J.F. ReHFELD \& K.A. MARCKER: Molecular cloning of human gastrin cDNA: Evidence for evolution of gastrin by gene duplication. Proc. Natl. Acad. Sci. USA 80, 2866-2869(1983)

3. Bornstein, P. \& G. Balian: Cleavage at AsnGly bonds with hydroxylamine. Meth. Enzymol. 47, 132-145 (1977)

4. Chirgwin, J.M., A.E. Przybyla, R.J. McDONALD \& W.J. RUTTER: Isolation of biologically active ribonucleic acid from sources en- 
riched in ribonuclease. Biochemistry 18, 52945299 (1979)

5. Dixon, H.B.F. \& R.N. Perham: Reversible blocking of amino groups with citraconic anhydride. Biochem. J. 109, 312-314 (1968)

6. Downs, F. \& W. Pigman: Determination of O-glycosidic linkages to L-serine and L-threonine residues of glycoproteins. Meth. Carbohyd. Chem. 7, 200- 204 (1972)

7. Dubois, M., K.A. Gilles, J.K. Hamilton, P.A. Rebers \& F. SMITH: Colorimetric method for determination of sugars and related substances. Anal. Chem. 28, 350-356 (1956)

8. EDMAN, P. \& A. BEGG: A protein sequenator. Eur. J. Biochem. 1, 80-91 (1967)

9. FäGERSTAM, L.G.: Cellulases from Trichoderma reesei QM 9414. Enzymatic and structural properties. Dissertation, Acta Universitatis Upsaliensis no. 610, Uppsala 1981

10. Fontana, A., D. Dalzappo, C. Grandi \& M. ZAMBONIN: Cleavage at tryptophan with o-iodosobenzoic acid. Meth. Enzymol. 91, 311318 (1983)

11. FreedberG, I.M., Y. Levin, C.M. Kay, W.D. McCubbin \& E. Katchalski-Katzir: Purification and charaterization of Aspergillus niger exo-1,4-glucosidase. Biochim. Biophys. Acta 391, 361-381 (1975)

12. Friedman, M., J.C. ZahNLEY \& J.R. WAGNeR: Estimation of the disulfide content of trypsin inhibitors as S- $\beta$-(2-pyridylethyl)-L-cysteine. Anal. Biochem. 106, 27-34 (1980)

13. Gum, E.K. \& R.D. Brown: Structural characterization of a glycoprotein cellulase, 1,4- $\beta$ D-glucan cellobiohydrolase $C$ from Trichoderma viride. Biochim. Biophys. Acta 446, 371-386 (1976)

14. Hagendüchle, O., R. Bovey \& R.A. Young: Tissue-specific expression of mouse $\alpha$-amylase genes: nucleotide sequence of isoenzyme mRNAs from pancreas and salivary gland. Cell 21, 179-187 (1980)

15. HAYASHIDA, S.: Selective submerged productions of three types of glucoamylases by a Black-koji mold. Agri. Biol. Chem. 39, 2093-2099 (1975)

16. Houmard, J. \& G.R. DRAPEAU: Staphylococcal protease: A proteolytic enzyme specific for glutamoyl bonds. Proc. Natl. Acad. Sci. USA 69, 3506-3509 (1972)

17. Inokuchi, K., T. Takahashi \& M. Irie: Purification and characterization of a minor glucoamylase from Aspergillus saitoi. J. Biochem. 90, 1055- 1067 (1981)

18. Johansen, J.T., C. Overballe-Petersen, B. Martin, V. Hasemann \& I. Svendsen: The complete amino acid sequence of copper, zinc superoxide dismutase from Saccharomyces cerevisiae. Carlsberg Res. Commun. 44, 201-217 (1979)

19. Jori, G., G. Galiazzo, A. Marzotto \& E. SCOFfone: Selective and reversible photo-oxidation of the methionyl residues in lysozyme. J. Biol. Chem. 243, 4272-4278 (1968)

20. KLAPPER, D.G., C.E. WILDE III \& J.D. CAPRA: Automated amino acid sequence of small peptides utilizing Polybrene. Anal. Biochem. 85, 126-131 (1978)

21. KLUH, I.: Amino acid sequence of hog pancreatic $\alpha$-amylase isoenzyme I. FEBS Letters 136 , 231-234 (1981)

22. LAEMMLI, U.K.: Cleavage of structural proteins during assembly of the head of bacteriophage T4. Nature 227, 680-685 (1970)

23. LINEBACK, D.R. \& L.A. AIRA: Structural characterization of two forms of glucoamylase from Aspergillus niger. Cereal. Chem. 49, 283-296 (1972)

24. Mahoney, W.C. \& M.A. Hermodson: Separation of large denatured peptides by reverse phase high performance liquid chromotography. Trifluoroacetic acid as a peptide solvent. J. Biol. Chem. 255, 11199-11203 (1980)

25. Mahoney, W.C., P.K. Smith \& M.A. HermodSON: Fragmentation of proteins with o-iodosobenzoic acid: Chemical mechanism and identification of o-iodosobenzoic acid and a reactive contaminant that modifies tyrosyl residues. Biochemistry 20, 443-448 (1981)

26. Marshall, R.D.: Glycoproteins. Annu. Rev. Biochem. 41, 673-702 (1972)

27. MaXam, A.M. \& W. Gilbert: A new method for sequencing DNA. Proc. Natl. Acad. Sci. USA 74, 560-564 (1977)

28. Miah, M.N.N. \& S. Ueda: Multiplicity of glucoamylase of Aspergillus oryzae. Part 1. Separation and purification of three forms of glucoamylase. Die Stärke 29, 191-196 (1977)

29. Montreuil, J.: Recent data on the structure of the carbohydrate moiety of glycoproteins. Metabolic and biological implications. Pure Appl. Chem. 42, 431-477 (1975)

30. MORT, A.J. \& D.T.A. LAMPORT: Anhydrous hydrogen fluoride deglycosylates glycoproteins. Anal. Biochem. 82, 289-309 (1977)

31. Nagata, Y., S. Suga, O. Kado \& B. Maruo: $\mathrm{N}$-terminal amino acid sequence of $\alpha$-amylase from Bacillus subtilis var. amylosacchariticus: Comparison with that of "liquefying" type $\alpha$-amylase. Agri. Biol. Chem. 44, 215-216 (1980) 32. Pazur, J.H. \& T. Ando: The action of an 
amyloglucosidase of Aspergillus niger on starch and malto-oligosaccharides. J. Biol. Chem. 234, 1966-1970 (1959)

33. Pazur, J.H., H.R. Knull \& A. Cepure: Glucoenzymes: Structure and properties of the two forms of glucoamylase from Aspergillus niger. Carbohyd. Res. 20, 83-96 (1971)

34. Pazur, J.H., Y. Tominaga, L.S. Forsberg \& D.L. SimPSON: Glycoenzymes: an unusual type of glycoprotein structure for a glucoamylase. Carbohyd. Res. 84, 103-114 (1980)

35. ReILly, P.J.: Starch hydrolysis with soluble and immobilized glucoamylase. Appl. Biochem. Bioeng. 2, 185-206 (1979)

36. Rosenthal, A.L. \& J.H. Nordin: Enzymes that hydrolyze fungal cell wall polysaccharides. The carbohydrate constitution of mycodextranase, an endo- $\alpha(1-4)$-D-glucanase from Penicillium melinii. J. Biol. Chem. 256, 5295-5303 (1975)

37. Rogers, J.C. \& C. Milliman: Isolation and sequence analysis of a barley $\alpha$-amylase cDNA clone. J. Biol. Chem. 258, 8169-8174 (1983)

38. RUNSwick, M.J. \& J.E. WALKER: The amino acid sequence of the $\beta$-subunit of ATP synthase from bovine heart mitochondria. J. Biol. Chem. 258, 3081-3089 (1983)

39. Schroeder, W.A., J.B. Shelton \& J.R. ShelTON: An examination of conditions for the cleavage of polypeptide chains with cyanogen bromide: Application to catalase. Arch. Biochem. Biophys. 130, 551-556 (1969)

40. Shoemaker, S., V. Schweickart, M. Ladner, D. Gelfand, S. KwoK, K. Myambo \& M. InNis: Molecular cloning of exo-cellobiohydrolase I derived from Trichoderma reesei strain L27. BIO/ TECHNOLOGY 1, 691-696 (1983)
41. Svendsen, I., B. Martin \& I. Jonassen: Characteristics of Hiproly barley III. Amino acid sequences of two lysine-rich proteins. Carlsberg Res. Commun. 45, 79-85 (1980)

42. Svensson, B.: Covalent cross-linking of porcine small-intestine microvillar aminopeptidase. Subunit structure of the membrane-bound and the solubilized enzyme. Carlsberg Res. Commun. 44, 417-430 (1979)

43. Svensson, B., K. LARSEN \& I. Svendsen: Amino acid sequence of tryptic fragments of glucoamylase G1 from Aspergillus niger. Carlsberg Res. Commun. 48, 517-527 (1983)

44. Svensson, B., T.G. Pedersen, I. Svendsen, T. SAKAI \& M. OtTESEN: Characterization of the two forms of glucoamylase from Aspergillus niger. Carlsberg Res. Commun. 47, 55-69 (1982)

45. Takahashi, T., Y. Tsuchida \& M. Irie: Purification and properties of three forms of glucoamylase from Rhizopus species. J. Biochem. 84, 1183-1194 (1978)

46. Täkkinen, K., R.F. Pettersson, N. Kalkkinen, I. Palva, H. Soderlund \& L. KAARIANEN: Amino acid sequence of $\alpha$-amylase from Bacillus amyloliquefaciens deduced from the nucleotide sequence of the cloned gene. $\mathrm{J}$. Biol. Chem. 258, 1007-1013 (1983)

47. Toda, H., K. Kondo \& K. Narita: The complete amino acid sequence of Taka-amylase A. Proc. Japan Acad. 58, Ser. B, 208-212 (1982)

48. Yoshino, E. \& S. Hayashida: Enzymatic modification of glucoamylase of Aspergillus awamori var. kawachi. J. Ferment. Technol. 56, 289-295 (1978)

49. UedA, S.: Fungal glucoamylase and raw starch digestion. Trends Biochem. Sci. 6, 89-90 (1981) 


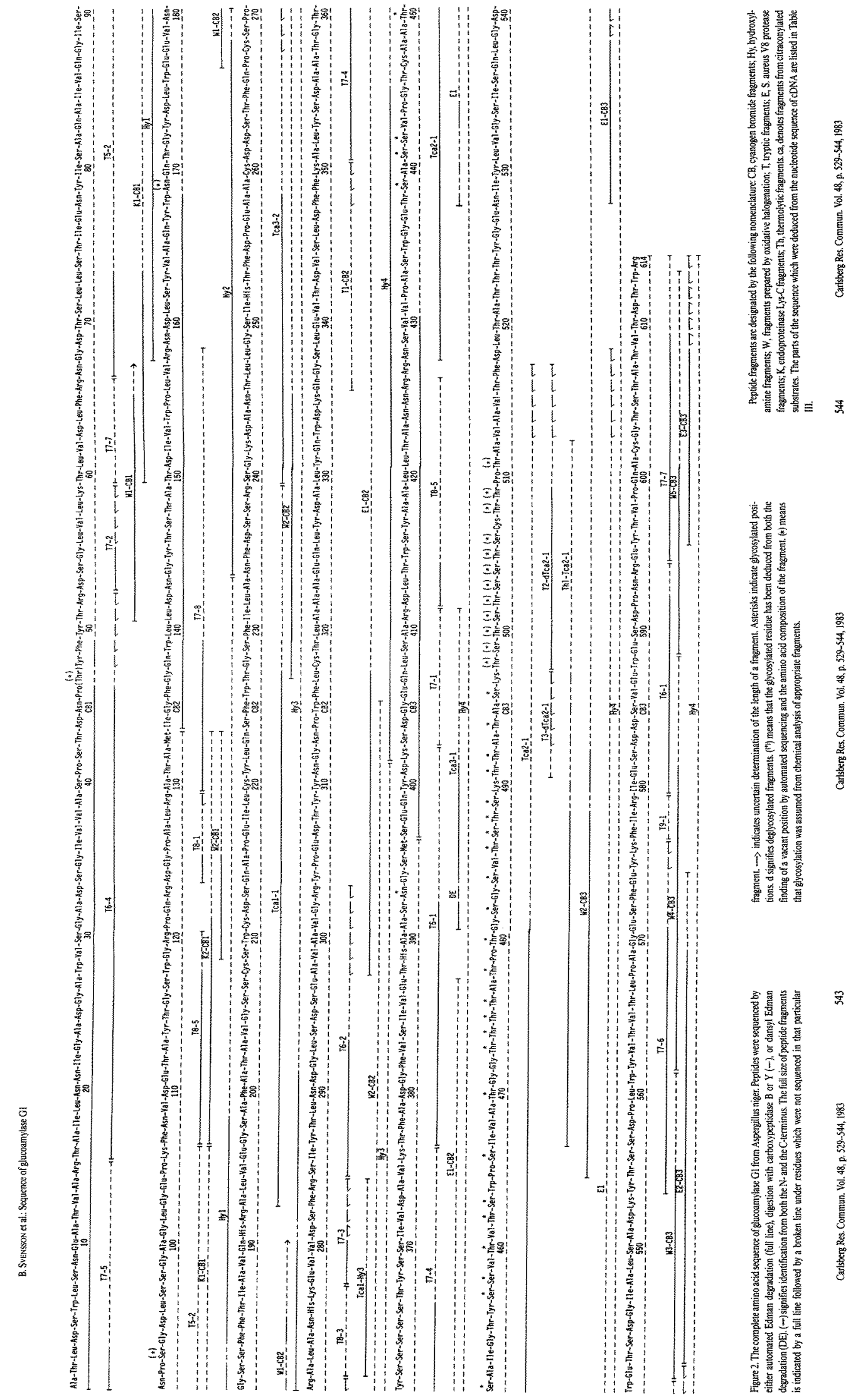

